\title{
HUMANIZAÇÃO E DESUMANIZAÇÃO NA ESCOLA: DE VOLTA ÀS LIÇÕES COMPLEXAS DE FREIRE
}

\section{HUMANIZATION AND DESUMANIZATION IN SCHOOL: BACK TO FREIRE COMPLEX LESSONS}

CAETANO, Vitor Nunes ${ }^{1}$ SILVA, Lincoln Tavares ${ }^{2}$

\section{Resumo}

A humanização é tratada em sua complexidade, no campo da educação básica. Recorremos às contribuições desenvolvidas por Paulo Freire, complementadas por ideias de humanização do campo da saúde (DESLANDES, 2006) e de Complexidade (MORIN, 2011). Com isso, caracterizamos a humanização e seu contraposto, a desumanização, como fios que compõem a tecitura de um fenômeno complexo. Associamos tal fundamentação aos sentidos humanizantes e desumanizantes de práticas captadas junto a estudantes do $5^{\circ}$ e $9^{\circ}$ anos do Ensino Fundamental da rede municipal do Rio de janeiro, conforme Moscovici (2003). A humanização na escola é tomada como processo formador, centrado na perspectiva freireana do Ser Mais, pensada com o despertamento das consciências dos estudantes como seres inconclusos, que necessitam de instrumentação para estar no mundo e com o mundo. Sendo assim, humanização e desumanização são práticas humanas, viabilidades históricas, que merecem centralidade e discussão permanentes.

Palavras-chave: Humanização; Complexidade; Representações Sociais; Educação Básica; Paulo Freire

\section{ABSTRACT}

Humanization is treated in its complexity, in the field of basic education. We used the contributions developed by Paulo Freire, complemented by ideas of humanization in the field of health (DESLANDES, 2006) and Complexity (MORIN, 2011). With this, we characterize the humanization and its contraposition, the dehumanization, like threads that compose a complex phenomenon. We associate this reasoning to the humanizing and dehumanizing senses of practices captured by students of the 5th and 9th grade of Rio de Janeiro municipal school according to Moscovici (2003). Humanization in the school is a formative process, centered in the Freirean perspective of Being More, thought with the awakening of the students' consciences as inconclusive beings, who need instrumentation to be in the world and with the world. Therefore, humanization and dehumanization are human practices, historical viabilities that deserve permanent centrality and discussion.

KeY WORDS: Humanization; Complexity; Social Representations; Basic education; Paulo Freire

\footnotetext{
${ }^{1}$ Mestre em Ensino em Educação Básica pelo Programa de Pós-Graduação de Ensino em Educação Básica do Instituto de Aplicação Fernando Rodrigues da Silveira (PPGEB/CAp-UERJ); Professor I da SME/RJ e da SEECUC-RJ. e-mail: vitornca@globo.com

${ }^{2}$ Doutor em Educação (FE-USP); Professor Adjunto da Universidade do Estado do Rio de Janeiro Instituto de Aplicação Fernando Rodrigues da Silveira; Professor do PPGEB/CAp-UERJ. e-mail: lincolnt@uerj.br
} 
DOI: $10.12957 /$ e-mosaicos.2017.31055

\section{INTRODUÇÃO}

A despeito dos impropérios descabidos e infundados, que nos últimos tempos vimos circular sobre a figura de Paulo Freire, é importante que se diga o seguinte: este nosso caro e saudoso Mestre da Esperança continua atualíssimo e absolutamente necessário, para aqueles que se dedicam à tecitura das reflexões que tenham como pauta esclarecer as questões que se colocam como aquelas mais prementes, que estão a afetar sobremaneira o campo da educação neste século 21 .

E se, nestes tempos, ainda nos deparamos com colapsos e insucessos no processo de escolarização de crianças e jovens, que são, por exemplo, apontados por baixos índices do IDEB, como aqueles apurados em 2013 para os anos iniciais e finais, em vários dos municípios e no estado do Rio de Janeiro, assim como na média nacional, diríamos para os críticos de Freire, que a razão disso reside, não na suposta presença ostensiva do pensamento de Freire, nas proposições e ações delineadas por ele para o sistema escolar brasileiro, mas sim na frustração dos intentos daqueles que continuam insistindo em colocar em prática os ensinamentos freireanos em favor de um outro panorama educacional.

No legado deixado por suas contribuições, existem ainda aspectos que merecem ser melhor explorados por nós educadores. Entre eles destacamos, neste texto, a superação dos imensos desafios que envolvem o processo de nossa humanização e sua relação com o processo de educação escolar. Debate este que traz nas considerações deixadas por Freire, desde a Pedagogia do Oprimido, uma marca de pioneirismo.

Sendo assim, o escopo deste artigo visa expor um recorte que fizemos das contribuições de Freire em torno do tema humanização, com base em trabalho de pesquisa que desenvolvemos. Não trataremos aqui da apresentação do percurso metodológico da pesquisa que realizamos. Nosso interesse se pauta em demonstrar, dentro do que apuramos sobre as considerações de Paulo Freire, complementadas com a ideia de complexidade de Edgar Morin, a validade e a pertinência da inserção da temática humanização/desumanização na ordem do dia dos debates na educação. Fenômeno este que se mostra, no entendimento a que chegamos, bem caracterizado no seio do cotidiano escolar.

A discussão que apresentamos teve o seu nascedouro e desenvolvimento na pesquisa de mestrado em ensino em educação básica, apresentada ao PPGEB/CAp- UERJ ${ }^{3}$, ocasião em que nos propusemos trazer centralidade à temática da humanização. Partindo de uma séria preocupação, estabelecida com a deterioração da relação de convivência entre os estudantes e os seus impactos sobre a escolarização de crianças e jovens e sua formação humana, seguimos por tentar melhor entender este objeto em sua complexidade. Disto resultou o trabalho de captação dos sentidos que professores e estudantes do $5^{\circ}$ e do $9^{\circ}$ anos, de uma unidade escolar pública municipal do Rio de janeiro, atribuem às práticas humanizantes que realizam, e as que se submetem ou são submetidos nas relações

3 PPGEB/CAp-UERJ - Programa de Pós-Graduação de Ensino em Educação Básica do Instituto de Aplicação Fernando Rodrigues da Silveira/UERJ. 
de convivência no cotidiano escolar. Tais práticas, que envolvem desde a recepção desses atores e o seu acolhimento no ambiente educacional; as ações de escolarização desenvolvidas junto aos estudantes; os modos de tratamento estabelecidos por estes atores no convívio social escolar; as condições materiais e ambientais disponibilizadas pelos empregadores aos profissionais das diferentes instâncias, para que as práticas escolares efetivamente aconteçam; entre outras; podem refletir ou refratar sentidos que caracterizamos como humanizantes ou desumanizantes.

Tomamos o cuidado de demonstrar não ser esta uma pesquisa de opinião, fundada sobre gostos e desgostos dos estudantes em relação às práticas escolares. Interessamos-nos em identificar, no conteúdo manifestado, quais rotinas se colocariam como favoráveis à evidenciação da vocação do Ser Mais, portanto humanizantes, na concepção de Paulo Freire. E, do mesmo modo, compreender quais delas seriam impeditivas de sua manifestação, sendo caracterizadas nesse sentido como desumanizantes. Os resultados a que chegamos podem ser acessados de forma integral em versão que se encontra disponível no sítio do PPGEB ${ }^{4}$.

O que nos propomos, então, neste artigo, é esclarecer quais os pontos de vista em que pautamos os alicerces de nossas inferências sobre a humanização, com base na pesquisa citada. E, nesse ínterim, apresentar os fundamentos sobre os quais defendemos a inserção da tratativa deste tema no centro do debate educacional. Nesse contexto, discutimos a fundamentação teórica do tema pela via da complexidade, recorrendo à triangulação entre os pensamentos de Paulo Freire e Edgar Morin, utilizando em conjunto os esclarecimentos de Suely Deslandes, que nos possibilitaram estabelecer diálogos interessantes entre os campos da educação e da saúde, em torno do objeto humanização, respeitadas às especificidades de cada área de conhecimento. Lançamos mão, também, de algumas contribuições da Teoria das Representações Sociais, formulada por Serge Moscovici, que serviu não só ao propósito de delineação do caminho metodológico da pesquisa, mas também nos permitiu um entendimento diferenciado do ser humano.

Muito embora, possa parecer não haver duvidas quanto à presença de um cunho eminentemente humanizador, recaindo sobre a dinâmica dos processos escolares, estranhamente, a humanização não é ainda um tema referencial, objeto agregador das mais importantes discussões do campo da Educação.

Humanização é uma palavra que dificilmente se pronuncia dentro das rodas de conversas, quais sejam elas comandadas por professores e/ou especialistas, ao se colocarem a criticar os insucessos e dissabores enfrentados no desenvolvimento dos processos formativos.

Quer fazendo referência aos conflitos existentes nas relações de convivência entre os diversos atores escolares, quer destacando as dificuldades encontradas por

4 CAETANO, V. N. Humanização e desumanização na escola: o que dizem os gostos e desgostos na tecitura complexa dos sentidos produzidos sobre as práticas escolares, 2016. <http://ppgebcapuerj.blogspot.com.br/p/blog-page_11.html> 
professores, no decurso das práticas escolares, para apresentar aos estudantes proposições que se mostrem significativas e interessantes a sua formação humana, escolarização, desenvolvimento, avaliação, instrução, desempenho, aprendizagem, discriminação, violência, racismo, bullying são palavras que se fazem bem mais presentes, e se destacam nos discursos e interesses que mobilizam esses profissionais.

No caminho da pesquisa, investigando preocupações sobre a humanização, inclusive fora do raio direto de ação da educação, nos chamou bastante atenção a tratativa dada ao tema pelo campo da saúde que, desde os anos 1970, alçou a humanização ao centro dos debates e a transformou em objeto de pesquisa. E no bojo das discussões que ali se apresentam, encontramos interessantes correlações. Muitas das quais poderiam resultar em potenciais benefícios ao campo da educação, isso se nos dispuséssemos a discuti-las sob a ótica dos problemas que enfrentamos, guardadas as especificidades presentes nessas áreas. É o que faremos, a seguir, brevemente.

\section{A COMPLEXIDADE NA HUMANIZAÇÃO: POSSIBILIDADES DE DIÁLOGO ENTRE SAÚDE E EDUCAÇÃO}

Os debates em torno da temática humanização vêm ocupando grande destaque no campo da saúde, intensificados desde a década de 1970, tanto em nível nacional quanto internacional. Isso, desapontando opiniões em contrário que viam, nesta controvérsia, algo que fosse comparável a um modismo ou conceito de ocasional, como salienta Deslandes (2006).

Minayo (2006), por sua vez, reitera que a temática humanização se coloca então como um importante movimento que se volta para a instituição do cuidado e da valorização da intersubjetividade nas relações entre pacientes e profissionais de saúde. Desse modo, pesquisadores e profissionais da área se puseram a discutir a humanização dos cuidados, como objeto de orientação das práticas voltadas aos usuários dos serviços de saúde.

No Brasil, Deslandes (2004) nos chama a atenção para o fato de que essa temática tenha desencadeado, em nível governamental, nos idos dos anos 2000, 0 estabelecimento de uma política pública desenvolvida pelo Ministério da Saúde, denominada Programa Nacional de Humanização da Assistência Hospitalar (PNHAH). Posteriormente, em seus desdobramentos, ela se constituiu em uma política de assistência que foi denominada de "Humaniza SUS".

Sob nosso ponto de vista, presenciamos entre as áreas de educação e saúde aspectos que denotam importantes similaridades. Em ambas as áreas, profissionais lidam com o objeto humano em termos de suas subjetividades. Quer pela via do cuidar, quando profissionais da saúde buscam tratar de pessoas/sujeitos em condição de fragilidade física ou psíquica, por vezes em difícil situação de sofrimento, quer pela via do ensinar, quando profissionais da educação assumem a tarefa formativa de sujeitos que, por vezes, se encontram em condições de fragilidade social, 
acompanhando-os em iniciativas escolarizantes, com vistas ao desenvolvimento humano de crianças e jovens. Para ambos os tipos de profissionais, em nosso entendimento, a discussão sobre humanização denotaria atenção não só ao resultado final da ação das práticas desenvolvidas, mas também aos modos como tais condutas se desenrolam, humanizantes e desumanizantes, para aqueles que são objetos do cuidar ou do ensinar.

Nas tratativas que no campo da saúde, referenciam discussões em termos da humanização dos cuidados em saúde, Deslandes (2006) cita a socióloga Jan Howard (1975) como importante referência no esforço de produção de modelos explicativos que pudessem trazer avanços ao quadro de uso flexível e pouco rigoroso dos termos humanização e desumanização, além da formalização de uma conceituação que possibilitasse operacionalizar a essa noção em variáveis de pesquisa.

No seu trabalho, Howard destaca um conjunto de 11 práticas desumanizantes e oito outras que seriam humanizantes. Alguns aspectos desumanizantes seriam: 0 tratamento de pessoas como coisas, ocorrendo quando não se reconhece no doente o seu status de sujeito, e sim como objeto de intervenção clínica, situação na qual, pessoas doentes são vistas como um conjunto de necessidades padronizadas a quem se oferecem serviços do mesmo modo estandardizados; a desumanização pela tecnologia, em que na prestação dos cuidados médicos haveria predominância da mediação de máquinas e procedimentos, em detrimento da interação entre a pessoa doente e seus cuidadores; ver a pessoa como problema, que denota a redução da pessoa doente à sua condição patológica, caso em que são ignorados as necessidades subjetivas e os conflitos vividos pelo sujeito quanto à situação em que se encontra; o tratamento de certas pessoas como sujeitos de menor valor, algo que ocorre quando se atribui aos doentes status e hierarquia dentro de um dado sistema social, influenciando no modo em que tais pessoas são tratadas, ao considerar certos pacientes como não pessoas, valoradas como inferiores aos demais; o isolamento de pessoas, naquelas circunstâncias relacionadas a internações que se prolongam, provocando distanciamento entre o paciente e seus cuidadores, despersonalizando o tratamento; tomar as pessoas como recipientes de cuidados padronizados, o que significa dispensar a certos pacientes ou grupos de pacientes cuidados inferiores ou de qualidade menor ao conhecimento ou tecnologia médica disponível, seja por indiferença, negligência ou discriminação; considerar pessoas sem escolha, que coloca em discussão a questão da autonomia e os graus de liberdade e suas antíteses envolvendo pacientes e cuidadores dentro de um dado modelo assistencial (CAETANO, 2016).

Na conceituação das condutas consideradas humanizantes, Howard (1975) identifica oito condições, que se encontram filiadas: às dimensões ideológicas, que estão relacionadas ao intrínseco valor da vida humana, à insubstituibilidade de cada ser humano e à perspectiva de considerar as pessoas em sua integralidade; às dimensões estruturais em que se dão as interações paciente-cuidador, que se relacionam à liberdade de ação de profissionais e pacientes, à manutenção do status de igualdade frente à assimetria do conhecimento específico do profissional em 
relação ao paciente e ao compartilhamento de decisões e responsabilidades no tocante ao cuidado a ser realizado; por fim à dimensão psicológica, envolvendo aspectos relacionados à empatia, que se traduziria na hiperidentificação do profissional com os problemas do paciente com a demanda de barreiras protetivas, e do afeto, ligado ao estabelecimento de vínculos afetivos entre pessoas doentes e seus cuidadores.

Diante disso, entendemos que em tais aspectos, encontramos pontos bastante tangenciais, remetendo a situações similarmente enfrentadas por profissionais da educação, no âmbito de nossas escolas. Imaginamos ser assaz pertinente pensar que crianças e jovens não devam ser, no processo de escolarização, tratados como recipientes de ações padronizadas e como sujeitos sem escolhas; e que possam, do mesmo modo, usufruir o direito de serem esclarecidos quanto aos processos a que são submetidos; e igualmente exercer algum poder de escolha, quanto a fazer proposições sobre aquilo que Ihe será ofertado como educação; não serem tratadas como sujeitos de menor valor em termos de hierarquia dentro de um sistema social. Nestas considerações encontramos elementos bastante relevantes, capazes de sustentar a razoabilidade de trazer do campo da saúde contribuições bastante pertinentes em torno da humanização, para os debates em educação.

Humanização e desumanização em Freire apresentam ares de complexidade. Ordem, desordem e organização são o que seria, em nosso entendimento, para Morin, as expressões deste fenômeno. Sendo assim, a desumanização se coloca, para alguns humanos, como força organizadora de um universo estável, onde a humanização se instaura como desordem, força desintegradora, geradora de caos. Do mesmo modo, a humanização se mostra para tantos outros como força organizadora de um universo paralelo, onde a desumanização por eles sofrida representa em igual escala, a face da desordem. Ambos os universos são tecidos juntos, se interpenetram, destroem-se mutuamente, esforçam-se por manterem-se íntegros.

Freire (1997, 2014 c) define a nossa vocação ontológica para a humanização, como aquela pautada pela possibilidade de exercermos poder decisório próprio, da feitura de ser sujeito, de ser para si. Tomada como força organizadora frente ao caos, podemos entendê-la como possibilidade de nos colocarmos no centro de nosso próprio mundo, como nos diz Morin (2011), sem, no entanto, ter que sacrificar os outros, mas sendo, contudo, capaz de até mesmo se sacrificar por eles.

E se elegemos a humanização, e não o seu contraposto, como a verdadeira vocação da humanidade, as relações entre humanos ganham, como grande significado, a ação de viabilizar a homens e mulheres serem respeitados em sua diversidade. Aquilo que Ihes seja necessário em condições para que o Ser Mais, em cada um deles, se expresse em plenitude. Ao revelar isto, Freire passa desmontar e embaraçar velhos modos de pensar. 


\section{MAS DE QUAL HUMANIZAÇÃO TRATAMOS?}

No desenvolvimento da pesquisa, foi preciso lidar com a (re) apresentação de um processo, a humanização. $E$ isto resultou também na necessidade de efetuar diferenciações com relação a um outro, o humanismo. Posto que, ambos os termos expressam sentidos bastante próximos, e que por vezes se confundem, gerando entendimentos incoerentes. Ao procedermos desse modo, foi possível destacar, primeiramente, juízos distintos, para o termo humanismo, que divergem daquele que é o sentido universal dado pelo senso comum.

Identificamos, nas diversas sociedades, múltiplos modos de ser e de viver humanos, mediados pela diversidade de crenças, valores, normas, práticas, ideologias e representações sociais. Nesta compreensão, se revelaram também aspectos da complexidade de Morin (2011, 2013, 2014), embebidos em um misto de ordem, organização e desordem, onde o "todo" do humanismo contempla tanto a multiplicidade de expressões de viver humanas, como ao mesmo tempo revela a existência de uma forma hegemônica de humanismo, que busca se impor a todos nós.

Esta complexidade vemos representada exemplarmente, por meio da doutrina humanista defendida pelo Chefe Seattle, na conhecida carta direcionada ao presidente americano Franklin Pierce, quando em 1854 fez a ele uma oferta de compra das terras de seu povo:

Sabemos que o homem branco não compreende o nosso modo de viver. Para ele um lote de terra é igual a outro, porque ele é um forasteiro que chega na calada da noite e tira da terra tudo o que necessita. A terra não é sua irmã, mas sim sua inimiga, e depois de a conquistar, ele vai embora, deixa para trás os túmulos de seus antepassados, e nem se importa. Arrebata a terra das mãos de seus filhos e não se importa. Ficam esquecidos a sepultura de seu pai e o direito de seus filhos à herança. Ele trata sua mãe - a terra - e seu irmão - o céu - como coisas que podem ser compradas, saqueadas, vendidas como ovelha ou miçanga cintilante. Sua voracidade arruinará a terra, deixando para trás apenas um deserto [...]De uma coisa sabemos. A terra não pertence ao homem: é o homem que pertence à terra, disso temos certeza. Todas as coisas estão interligadas, como o sangue que une uma família. Tudo está relacionado entre si. Tudo quanto agride a terra, agride os filhos da terra. Não foi o homem quem teceu a trama da vida: ele é meramente um fio da mesma. Tudo o que ele fizer à trama, a si próprio fará. ${ }^{5}$

\footnotetext{
${ }^{5}$ Disponível em: http://www.ufpa.br/permacultura/carta_cacique.htm. Acesso em: 01/03/2016.
} 
Neste humanismo dos "peles vermelhas", o homem não é colocado como elemento central, mas como alguém situado no mundo e com o mundo. Denota-se que, para além do hegemônico, outros humanismos são possíveis. Tal vertente estabelece significativas criticas tanto ao humanismo do cosmo, difundido pelos gregos, como ao humanismo hegemônico, que se configurou na Europa e se espalhou mundo afora, a partir do século XIX. Humanismo este que se impôs como doutrina, fazendo o homem ascender posição sobre as coisas do mundo:

[...] conjunto de doutrinas fundamentadas de maneira precípua nos interesses, potencialidades e faculdades do ser humano, sublinhando sua capacidade para a criação e transformação da realidade natural e social, e seu livre-arbítrio diante de pretensos poderes transcendentes, ou de condicionamentos naturais e históricos (HOUAISS, 2007, p. 1554).

A hegemonia deste humanismo se manifesta, como apuramos, nos vocábulos referentes a "família humana" presentes no dicionário Houaiss (2001). Naquela que seria a sua versão linguística, temos os sentidos dados a: human, humanar, humanado, humanidade, humanismo, humanista, humanitarismo, humanização, humanizado, humanizador, humano e humanoide. Sobressaem-se nesses sentidos, além dos aspectos biológicos, as características do agir social, a exaltação da capacidade criativa, as boas práticas, o bom agir humano. Mas também nos deparamos com a contradição, que não referencia a mulher como legítimo representante humano dentro desse vocábulo:

Bio mamífero da ordem dos primatas, único representante vivente do gen. Homo, da espécie Homo sapiens, caracterizado por cérebro volumoso, posição ereta, mãos preênseis, inteligência dotada da faculdade de abstração e generalização, e capacidade para produzir linguagem articulada [...] a espécie humana: a humanidade [...] o ser humano considerado em seu aspecto morfológico, ou como tipo representativo de determinada região geográfica ou época [...] indivíduo do sexo masculino (HOUAISS, 2007, p. 1545).

Acompanhando o sentido proposto ao verbete, uma série de composições sugerem denominações que visam ressaltar atributos sociais positivos da figura masculina da espécie humana, tais como: homem-bom, homem-chave, homem-feito, homem-gol, homem-grande, homem-mosca, homem-pássaro, homem-rã. Tais atributos se relacionam à capacidade de ser altruísta, à manifestação de respeitabilidade, de habilidades atléticas, ao talento para a tomada de decisões frente a desafios. No entanto, em contraposição vemos a evocação de sentidos que não conferem à mulher um mesmo destaque: 
Indivíduo do sexo feminino, considerado do ponto de vista das características biológicas, do aspecto ou forma corporal, como tipo representativo de determinada região geográfica, época, etc [...] aquela que tem sua fisiologia e sua vida genital percebidas como essência do ser humano feminino em sua evolução [...] o ser humano feminino considerado em conjunto, ideal ou concretamente[...] a fêmea humana como parceira sexual (HOUAISS, 2007, p.1976).

Para a mulher, numa série de composições que acompanham o verbete, o que se ressalta, em sua maioria, é uma nítida disposição de desqualificação da figura feminina, de torná-la menor, de desumanizá-la. Isto pode ser visto nos verbetes que se seguem: mulher à toa, mulher da comédia, mulher da rua, mulher da vida, mulher da zona, mulher de amor, mulher de casa, mulher-objeto, mulher de negócios, mulher honesta, mulher parideira, mulher séria. Em tais atributos são salientados aspectos de subalternidade e de cunho sexual, de forma a posicioná-la como parceira reprodutora ou objeto de prazer, numa condição explícita de propagandear uma suposta inferioridade frente ao homem. $E$ isto faz por ofuscar a capacidade de ser altruísta, a manifestação de respeitabilidade e de habilidades atléticas e o talento para a tomada de decisões frente a desafios, dos quais também é a mulher detentora.

Palavras são, nesse contexto, muito mais do que carreadores de significados, demonstram sua força na constituição de sentidos que referenciam a racionalidade hegemônica:

Na realidade, não são palavras o que pronunciamos ou escutamos, mas verdades ou mentiras, coisas boas ou más, importantes ou triviais, agradáveis ou desagradáveis, etc. A palavra está sempre carregada de um conteúdo ou de um sentido ideológico ou vivencial. É assim que compreendemos as palavras e somente reagimos àquelas que despertam em nós ressonâncias ideológicas ou concernentes à vida (BAKHTIN, 2006, p. 96).

Entendemos que a palavra seja então

[...] uma construção social, forjada na relação entre humanos e destes com o seu ambiente. Carrega em si um significado que pode tanto atender a uma intenção e orientar sentidos numa dada direção, como nas ideologias, ou responder a necessidade de explicar fenômenos do cotidiano e orientar condutas, sem que tal ação carregue em si uma intencionalidade, como pode ser visto em processos de formação do senso comum, quando grupos 
compartilham ideias, que carreiam explicações sobre como a realidade funciona (CAETANO, 2016, p. 57).

Acompanhando o pensamento de Bakhtin, não são somente palavras que pronunciamos quando falamos sobre humanismo ou humanização.

Em nosso entendimento, relacionamos o humanismo aos diversos modos de ser e de viver, que se expressam em todos os espaços sociais, inclusive o escolar. Já à humanização associamos, mais especificamente, as condutas que são praticadas e que, de certo modo, moldam o humano que há em nós. O ser humano neste processo pode ser entendido como um ser que é tecido pelas tramas do biológico e do social.

O homem é um ser evidentemente biológico. É ao mesmo tempo um ser evidentemente cultural, metabiológico e que vive em um universo de linguagem, de ideias e de consciência. Ora, estas duas realidades, a realidade biológica e a realidade cultural, o paradigma de simplificação nos obriga a disjuntá-las ou a reduzir o mais complexo ao menos complexo. Vamos, pois, estudar o homem biológico no departamento de biologia, como um ser anatômico, fisiológico etc. $\mathrm{E}$ estudar o homem cultural nos departamentos das ciências humanas e sociais. Vamos estudar o cérebro como órgão biológico e vamos estudar a mente, the mind, como função ou realidade psicológica. Esquecemos que um não existe sem a outra, ainda mais que um é a outra ao mesmo tempo, embora sejam tratados por termos e conceitos diferentes (MORIN, 2011, p. 59).

Neste movimento, Morin nos explica que a ciência seguiu orientada pela disjunção e pela simplificação, constituindo o que ele denomina de paradigma simplificador de conhecimento. Suas explicações construíram uma compreensão compartimentalizada do processo de humanização, responsável por fragmentar e particularizar o entendimento do que seja o humano. Muito embora, em termos de conhecimento, as contribuições suscitadas por esta vertente paradigmática tenham se tornado relevantes, isoladamente, as vias da disjunção e da simplificação não foram suficientes, para explicar o ser humano em sua totalidade. É neste aspecto, que notamos a aproximação entre as reflexões propostas por Morin, Freire e de outro autor, que também se espelha na condição social, Moscovici (2013). Todos consideram a fragilidade da primazia da reificação do conhecimento, no tocante à compreensão do fenômeno humano. Cada um deles, na sua especificidade: Morin, ressaltando os problemas causados pela disjunção existente entre os conhecimentos produzidos pelas diversas áreas; Moscovici, desenvolvendo a Teoria das Representações Sociais, tornando relevante que os saberes produzidos pelos universos consensuais, sejam matéria de compreensão do humano, e que, neste entendimento, a cultura não seja algo a ser defendida, nem refutada pela ciência: 
[...] Dito isso, é óbvio que o estudo das representações sociais deve ir além de tal visão e deve fazer isso por uma razão específica. Ela vê o ser humano enquanto ele tenta conhecer e compreender as coisas que o circundam e tenta resolver os enigmas centrais de seu próprio nascimento, de sua existência corporal, suas humilhações, do céu que está acima dela, dos estados da mente de seus vizinhos e dos poderes que o dominam: enigmas que o ocupam e preocupam desde o berço e dos quais ele nunca para de falar. Para ele, pensamentos e palavras são reais - eles não são apenas epifenômenos do comportamento (MOSCOVICI, 2013, p.42-43).

E Freire, evidenciando que a condição normal do ser humano não é a de um expectador passivo, de alguém que somente esteja no mundo, mas com ele. Capaz de

[...] travar relações permanentes com este mundo, de que decorre pelos atos de criação e recriação, o acrescentamento que ele faz ao mundo natural, que não fez, representado na realidade cultural. E de que, nestas relações com a realidade e na realidade, trava o homem uma relação específica - de sujeito para objeto - de que resulta 0 conhecimento, que expressa pela linguagem. Esta relação, como já ficou claro, é feita pelo homem, independentemente de se é ou não alfabetizado. Basta ser homem para realizá-la. Basta ser homem para ser capaz de captar os dados da realidade. Para ser capaz de saber, ainda que seja este saber meramente opinativo. Daí que não haja ignorância absoluta, nem sabedoria absoluta. O homem, contudo, não capta o dado da realidade, o fenômeno, a situação problemática pura. $\mathrm{Na}$ captação, juntamente com o problema, com 0 fenômeno,capta também seus nexos causais. Apreende a causalidade. A compreensão resultante da captação será tão mais crítica quanto seja feita a apreensão da causalidade autêntica. E será tão mais mágica, na medida em que se faça com um mínimo de apreensão dessa causalidade. Enquanto para a consciência crítica a própria causalidade autêntica está sempre submetida à sua análise o que é autêntico hoje pode não ser amanhã - para a consciência ingênua, o que lhe parece causalidade autêntica já não é, uma vez que Ihe atribui caráter estático, de algo já feito e estabelecido (FREIRE, 2014 a, p. 137-138).

O ser humano é, portanto, um ser complexo. E aquilo que dá sentido tanto à sua humanização, como processo, quanto à sua desumanização, se constitui como algo que se constrói pelas e nas relações socioculturais, mantidas pelos diversos atores humanos, presumidamente "fundamentadas e caracterizadas por representações", nas múltiplas interações que esses atores mantêm entre si, como 
nos aponta Moscovici (2013, p.40). Representações sociais se constituem, para o autor, como um

(...) sistema de valores, ideias e práticas, com uma dupla função: primeiro, estabelecer uma ordem que possibilitará as pessoas orientar-se em seu mundo material e social e controlá-lo; e, em segundo lugar, possibilitar que a comunicação seja possível entre os membros de uma comunidade, fornecendo-Ihes um código para nomear e classificar, sem ambiguidade, os vários aspectos de seu mundo e da sua história individual e social (MOSCOVICI, 1976 Apud DUVEEN, 2013, p.21).

Representações surgem das relações mantidas entre os sujeitos, em função das interações, retroações e determinações que se manifestam no mundo fenomênico, marcadas pelo contraditório, e pelo movimento de ordem, desordem e organização sobre o qual Morin (2011) nos fala. Aquilo que homens e mulheres pensam a respeito de humanização, em sua natureza representacional, é produzido na tecitura dessas relações e, desse modo, circula por meio dos processos comunicativos, se reconfigurando cotidianamente, tendo como matriz a humanidade inconclusa que há em nós, como ressalta Freire (1997, 2014a, 2014c, 2014d). São por essas interações que os sentidos de ser humano são tecidos e isso se dá tanto a partir da gama de sentidos de fatos já comumente conhecidos, como também pela inclusão de episódios que se mostram como absolutamente novos, gerados pelo surgimento de fenômenos estranhos, não familiares, cuja realidade dinâmica venha a nos apresentar.

Freire toma ainda a humanização como um problema crítico, dramático a ser enfrentado para a compreensão do seu lugar no mundo e com o mundo

Mais uma vez os homens, desafiados pela dramaticidade da hora atual, se propõem, a si mesmos, como problema. Descobrem que pouco sabem de si, de seu "posto no cosmos", e se inquietam por saber mais. Estará, aliás, no reconhecimento do seu pouco saber de si uma das razões desta procura. Ao instalar-se na quase, senão trágica descoberta do seu pouco saber de si, se fazem problema a eles mesmos. Indagam. Respondem, e suas respostas os levam a novas perguntas. $O$ problema de sua humanização, apesar de sempre dever haver sido, de um ponto de vista axiológico, o seu problema central, assume, hoje, caráter de preocupação iniludível (FREIRE, 2014c, p. 39).

Nesse sentido tomamos de Freire $(1997,2014 c)$ o conceito de humanização, em que ele manifesta a existência em nós de uma vocação ontológica de nos humanizarmos. Vocação para ele caracterizada pela busca de Sermos Mais, que se 
coloca como um propósito básico e permanente de nossa existência. No entanto, reconhecendo também nessa busca, a presença do seu contraposto, a desumanização, que se impõe como força contrária e impeditiva da concretização daquela que seria a verdadeira vocação dos seres humanos

Constatar esta preocupação implica, indiscutivelmente, em reconhecer a desumanização, não apenas como viabilidade ontológica, mas como realidade histórica. É também, e talvez sobretudo, a partir desta dolorosa constatação, que os homens se perguntam sobre a outra viabilidade - a de sua humanização. Ambas, na raiz de sua inconclusão, que os inscreve num permanente movimento de busca. Humanização e desumanização, dentro da história, num contexto real, concreto, objetivo, são possibilidades dos homens como seres inconclusos e conscientes de sua inconclusão. Mas, se ambas são possibilidades, só a primeira nos parece ser o que chamamos de vocação dos homens. Vocação negada, mas também afirmada na própria negação. Vocação negada na injustiça, na exploração, na opressão, na violência dos opressores. Mas afirmada no anseio de liberdade, de justiça, de luta dos oprimidos, pela recuperação de sua humanidade roubada (FREIRE, 2014c, p. 40).

Para Freire, os sujeitos se reconhecem como seres incompletos e conscientes de sua incompletude. Revelando, como já ressaltamos, aspectos da complexidade discutida por Morin, também fundamentados e caracterizados por representações, compartilhadas pelo senso comum, como nos esclareceu Moscovici. Percepções que nos convidam a cultivar outro olhar sobre a realidade, de forma a encará-la na perspectiva do todo, do que é tecido junto, o que inclui também suas contradições e desordens.

Em pesquisa realizada, Caetano (2016) pode evidenciar que atores escolares compartilham, em suas práticas cotidianas, todo um arcabouço de crenças, valores e normas e que estas são objetivadas na manifestação de condutas humanizantes e desumanizantes. $E$ nas narrativas informais de colegas professores e nas evocações dos estudantes, encontramos, por vezes, elementos que denotam dor, sofrimento, constrangimento, inquietação; além de fortes exemplos, em que temos cenários que caracterizam atentados contra o caráter de respeito mútuo e dignidade humana, no que se refere tanto a aspectos pessoais, quanto profissionais. E destas decorrem situações humilhantes, vexatórias, angustiantes, e que impactam, sobremaneira, as relações que se estabelecem entre estudantes e seus professores, e também entre esses professores e seus empregadores, em torno do processo de escolarização.

No entanto, com o que apuramos aos estudantes, utilizando a Técnica de Associação Livre de Palavras, a expressão do contraditório se fez presente. Utilizando as expressões indutoras "o que gosta de fazer na escola" e "o que não gosta de fazer na escola", chegamos a um conjunto de ideias que os estudantes utilizam para organizar o pensamento para o tema, sob a forma de Discurso do Sujeito Coletivo, 
entre coisas que sejam para eles, gostáveis ou não de serem praticadas no cotidiano escolar. E a partir do exposto fomos capazes de reconhecer aspectos humanizantes e desumanizantes. A compreensão dos elementos que compõem a tecitura complexa das práticas escolares nos permite reconhecer, dentre os seus aspectos positivos e negativos, os impactos que estes possam exercer sobre a convivência, mas também reconhecer as idealizações que se produzem com relação a estas práticas.

As análises apontaram especial destaque em torno da aula, seja ela legal ou chata, e ao ato de estudar, ora como elementos positivadores do processo de formação dos estudantes, ora como elementos de rejeição. Positivamente, o que se evidencia nestas falas, tanto em relação à aula e ao estudo, é a forte influência dada pelos estudantes a estes elementos, como essenciais a concretude da transformação do curso de suas vidas. E isto, por vezes, converge, mesmo de forma idealizada, ao que se coloca como afirmação da vocação ontológica do Ser Mais. Para estes atores, estudar se apresenta como possibilidade de aprender coisas, definidora do futuro, garantia de uma vida boa. Mas também se faz reduzido a um sentido utilitário, quando o estudo é tomado como meio para passar de ano.

No entanto, o contraditório que por estes termos se explicita, indica que a afirmação desta vocação, não se fará por meio de qualquer aula ou por qualquer forma de estudar. Neste contexto, os estudantes parecem ressaltar alguns aspectos capazes de conferir êxito as aulas: que sejam interessantes e essenciais, que proporcionem momentos de brincadeiras e divertimento com os amigos. Também evidenciam aspectos presentes nas práticas escolares que são geradoras de rejeição, colocando o estudante em uma condição de sujeito sem escolha: sem estudar não passo de ano, estudar é chato, mas é preciso, mesmo não tendo muitas coisas que me interessem. Há ainda queixas centradas sobre atividades que causam incômodos físicos e mentais, em que preponderam tarefas de cunho teórico sobre as práticas, por vezes confusas, e de difícil entendimento: Não gosto porque é difícil, muito confuso, não consigo entender. Fico com dor de cabeça. Estudar cansa a mão. Tem que copiar muito texto. Os professores passam muito trabalho e minha mão cansa. Você fica muito tempo escrevendo. Eu odeio fazer e armar contas, porque eu sou ruim e não consigo fazer.

Por fim, a conduta arrogante, ignorante, de não escuta dos estudantes exercida por alguns professores é também apontada como fator que contribui para sobre a aula e o ato de estudar, uma forte rejeição: Não gosto de assistir porque a professora é uma velha ignorante, abusada, arrogante e não escuta os alunos. É estranha e meio escrota com as pessoas. A professora é bipolar. A professora é chata e irritante, não tem senso. Não suporto ela, mas tenho que aturar. O professor é chato. É muito chatão, pega no nosso pé e isso é um saco.

\section{POR FIM...}

Nos seus escritos, Freire demonstra ainda não ser possível compreender a humanização somente pelo que ela é, salientando que se faz necessário reconhecer 
também aquilo que ela evidentemente não é, caracterizado na figura do seu contraposto a desumanização. Por isso, Freire reconhece, em ambas, viabilidades ontológicas e viabilidades na história.

Freire assim nos mostra a sua faceta complexa. Muito embora não restem dúvidas de que seja o Ser Mais a expressão da humanização, dessa nossa verdadeira vocação. Mas, em nenhum momento, em parte alguma dos seus textos, define ele o que isto significaria para cada um de nós. E não o faz porque toma este significado, como algo que se faz peculiar para cada sujeito.

Sendo assim, em nosso entendimento, não faz o menor sentido apregoar que seja Freire um pai fundador de um novo humanismo, pois isto é algo que soa como absolutamente desconexo ao que ele defendia.

Para Freire, existem diversas formas de expressão do humanismo, e todas merecem ser respeitadas. Isto é algo que ele deixa bastante claro em muitos momentos de sua obra, nos diálogos que manteve com toda gente que conviveu.

Mais do que querer propagar uma dada forma de humanismo, o que propõe Freire é o justo respeito às diferentes formas de sermos humanos, propondo reflexões sobre formas hegemônicas de humanismo. Freire então nos fala, chama atenção para práticas humanas, daí a humanização e a desumanização serem apresentadas como viabilidades históricas, algo que mereça centralidade e discussão permanente.

A humanização na escola, tomada como processo formador, centrado na perspectiva do Ser Mais, do qual nos falava Freire, pensa no despertamento das consciências dos estudantes como seres inconclusos, mas também ressalta a importância de ser instrumentado para estar no mundo e com o mundo.

No interesse do trabalho formativo, que a escola se propõe a fazer, imaginamos como inadmissível que práticas desumanizantes possam ser admitidas ao processo. No entanto, o contraditório é algo que ali notoriamente se estabelece. Tais práticas são claramente observáveis, circulam pelos ambientes escolares e são, por seus atores, compartilhadas e naturalizadas. Nosso interesse, nessa questão, passa a ser então compreender a forma como esse contraditório desumanizante se estabelece, tanto no que se refere às relações mantidas entre professores e estudantes, quanto ao que se processa na relação entre os professores, suas chefias diretas e seus empregadores, pois visamos, como educadores que buscam a emancipação com a inclusão do outro, caminhar com a superação de obstáculos que impeçam ou dificultem o empoderamento do seu próximo. 


\section{REFERÊNCIAS BIBLIOGRÁFICAS}

BAKHTIN, M. Marxismo e filosofia da linguagem. 12. ed. São Paulo: Hucitec, 2006.

CAETANO, V. N. Humanização e desumanização na escola: o que dizem os gostos e desgostos na tecitura complexa dos sentidos produzidos sobre as práticas escolares. Dissertação (Mestrado de Ensino em Educação Básica) Instituto de Aplicação Fernando Rodrigues da Silveira/UERJ 2016. 274f.

<http://ppgebcapuerj.blogspot.com.br/p/blog-page_11.html>

DESLANDES, S. F.. Análise do discurso oficial sobre a humanização da assistência hospitalar. Ciênc. saúde coletiva [online]. 2004, vol.9, n.1, pp.7-14. ISSN 14138123. http://dx.doi.org/10.1590/S1413-81232004000100002.

Humanização revisitando o conceito a partir das contribuições da sociologia médica. In: DESLANDES SF (org.). Humanização dos cuidados em saúde: conceitos, dilemas e práticas. Rio de Janeiro: Fiocruz; 2006. p. 33-47.

DUVEEN, G. O poder das ideias, p. 7 - 23. In MOSCOVICI, S. Representações Sociais: Investigações em Psicologia Social. (10ª ed.) Petrópolis: Vozes, 2013.

FREIRE, P. Papel da Educação na Humanização. Rev. da FAEEBA, Salvador, n. 7, p. 917, jan./jun. 1997

2014 a.

Educação como Prática da Liberdade. 36. ed. Rio de Janeiro: Paz e Terra,

Pedagogia da Esperança. 21. ed. Rio de Janeiro: Paz e Terra, 2014 b.

Pedagogia do Oprimido. 57. ed. Rio de Janeiro: Paz e Terra, 2014 c.

Pedagogia da Autonomia. 49. ed. Rio de Janeiro: Paz e Terra, 2014 d.

HOUAISS, A.; VILLAR, M. S. Dicionário HOUAISS da Língua Portuguesa. Rio de Janeiro: Objetiva, 2001.

HOWARD, J. Humanizing health care. Wiley, 1975.

MINAYO, M. C. S. Sobre o Humanismo e a Humanização. In: DESLANDES S.F (org.). Humanização dos cuidados em saúde: conceitos, dilemas e práticas. Rio de Janeiro Fiocruz; 2006. p. 23-30.

MORIN, E. Introdução ao Pensamento Complexo. Tradução do francês: Eliane Lisboa - Porto Alegre: Ed. Sulina, 2011.

Educação e complexidade: Os sete saberes e outros ensaios. ALMEIDA, M.

C. e CARVALHO, E. A. (orgs.) - 6. ed. - São Paulo: Cortez, 2013. 
e-Mosaicos - Revista Multidisciplinar de Ensino, Pesquisa, Extensão e Cultura do Instituto de Aplicação Fernando Rodrigues da Silveira (CAp-UERJ) V. 6 - N. 13 - DEZEMBRO 2017 - ISSN: 2316-9303

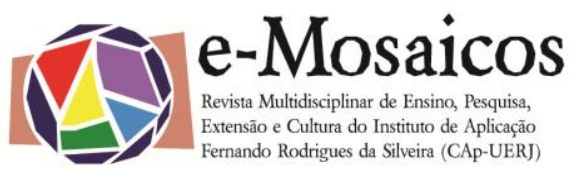

DOI: $10.12957 /$ e-mosaicos.2017.31055

A cabeça bem feita: repensar a reforma, reformar o pensamento. Tradução Eloá Jacobina - 21a. ed. - Rio de Janeiro: Bertrand Brasil, 2014.

MOSCOVICI, S. Representações Sociais: Investigações em Psicologia Social. (10ª ed.) Petrópolis: Vozes, 2013.

Recebido em 15 de outubro de 2017

Aceito em 10 de novembro de 2017 